\section{Dentists set to benefit from bespoke BDA indemnity scheme}

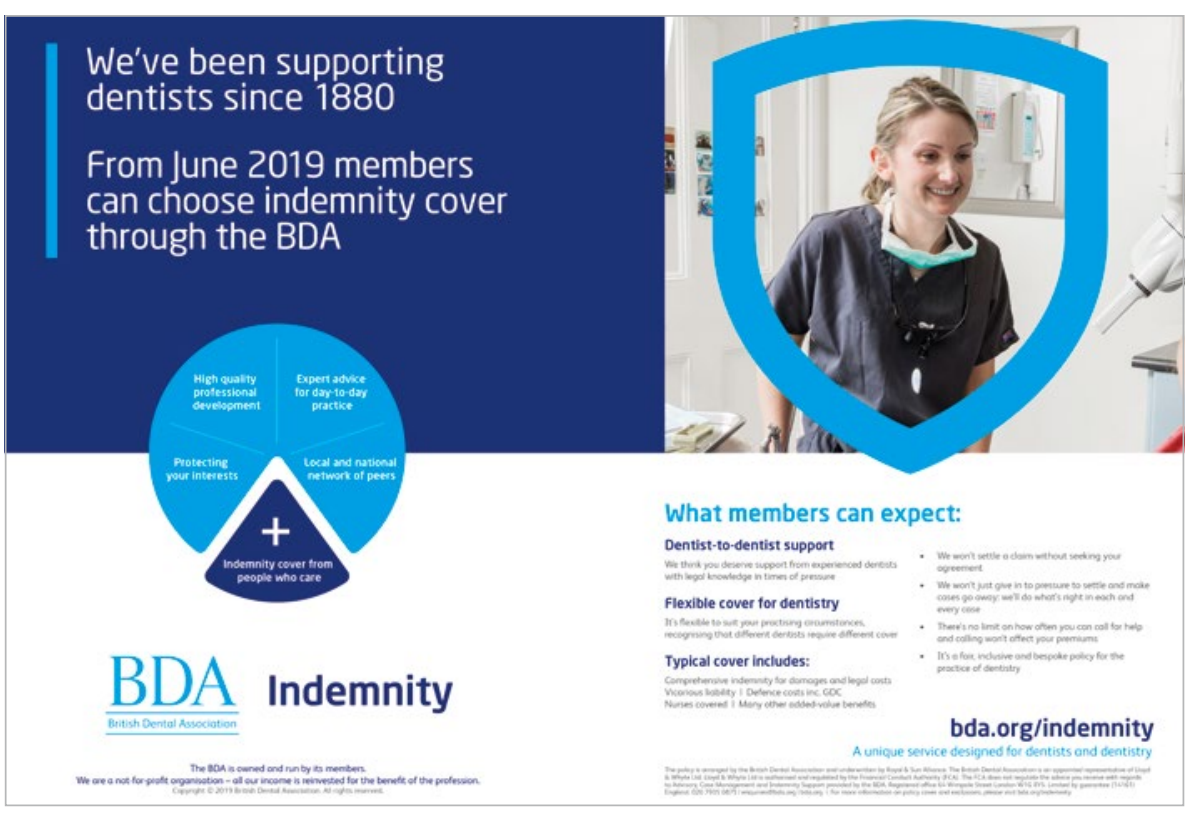

Dentists throughout the UK are to be offered a unique, new bespoke indemnity scheme by the BDA starting this summer, promising unlimited dentist-to-dentist support.

The BDA indemnity scheme will begin on 3 June 2019 offering union members unlimited access to support and advice from experienced dentists with legal knowledge, comprehensive indemnity for damages and legal costs, vicarious liability, defence costs including those for General Dental Council issues, and other benefits.

BDA Managing Director Peter Ward said: 'It's a fully comprehensive scheme to provide indemnity and professional support to dentists practising in the UK. It's only for dentists but excludes maxillofacial surgery. The benefit of confining the pool is that it means this is all about dentists and there is no confusion about cross-subsidy either in other countries or with different professions.'

The professional association and trade union has hired a dento-legal team to lead on the scheme as Dr Ward said: 'We have a team of dentally qualified advisers who will be the point of person contact. They will take queries, comments, questions - anything to do with the practising situation for the dentist in the clinical context. They will advise, support and be a friendly voice.
'If things get to the point where there is a need for legal representation or financial redress, those cases will be tapped into our insurance partner, Royal \& Sun Alliance, and they will be able to access the financial and other support on behalf of the members to help them deal with problems as they arise.

'Those things are really important because the vast majority of incidents of this type don't actually get to litigation, but having a friendly voice and a supportive, experienced dentist on the end of the phone can help to reassure them and take action to avoid things getting out of hand.

'There will be different levels of cover available depending on the individual's need. BDA members will be able to access an online 'click and quote' system which will ask six questions before providing an indicative quote for their bespoke indemnity cover. This quote is then subject to an underwriting assessment.

'The cost will depend on the dentist, how many days a week they work, whereabouts they are in the UK, what their standing is in the practice, said Dr Ward.

There will be three broad layers of cover:

- For a practice owner, there is a policy that covers them as a clinician and also their interaction with other clinicians in that management ownership relationship
- A detailed product available for those who are associates working as dentists but do not own the practice

- A layer for practitioners who work in a salaried service who are protected by Crown indemnity or employer's liability but the scheme protects them as individuals.

For dentists already covered with another indemnity provider, they can get a quote for the BDA's scheme before they choose to switch to the BDA once their existing scheme expires.

The BDA's scheme is different to existing ones, according to Dr Ward, who added: 'It's occurrence-based cover which means, as long as your policy is in force at the point where any incident happens, it doesn't matter when the complaint comes in - even if it's years later - your cover will endure. It's enduring cover.

'Also, it is contractually based, underpinned by a leading insurer and subject to an insurance contract. Consequently, unlike some of the current arrangements on the market which are discretionary and where it is up to the provider whether or not they cover you, with the BDA scheme you will receive a policy and know exactly what you are covered for.

'Another thing that is different about this scheme is that the BDA exists only for the benefits of members and has no other purpose.

'Our aim is that for the total price of BDA membership and the indemnity product all-inclusive, we intend to compete with the simple indemnity price of other organisations. Ours is a complete offering with the indemnity cover and the whole suite of other services we provide to members such as advice on employment law, NHS contracts, and compliance.'

Acknowledgments

The policy is arranged by the British Dental Association and underwritten by Royal \& Sun Alliance. The British Dental Association is an appointed representative of Lloyd \& Whyte Ltd. Lloyd \& Whyte Ltd is authorised and regulated by the Financial Conduct Authority (FCA). The FCA does not regulate the advice you receive with regards to Advisory, Case Management and Indemnity Support provided by the BDA. Registered office 64 Wimpole Street London W1G 8YS. Limited by guarantee (14161) England. 